\title{
Coverage and equity of maternal and newborn health care in rural Nigeria, Ethiopia and India
}

\author{
Tanya Marchant PhD, Emma Beaumont MSc, Krystyna Makowiecka MSc, Della Berhanu PhD, Tsegahun Tessema MA, \\ Meenakshi Gautham PhD, Kultar Singh PGDip, Nasir Umar PhD, Adamu Umar Usman MSc, Keith Tomlin MSc, \\ Simon Cousens MA, Elizabeth Allen PhD, Joanna Armstrong Schellenberg PhD
}

Cite as: CMAJ 2019 October 28;191:E1179-88. doi: 10.1503/cmaj.190219

\begin{abstract}
BACKGROUND: Despite progress toward meeting the Sustainable Development Goals, a large burden of maternal and neonatal mortality persists for the most vulnerable people in rural areas. We assessed coverage, coverage change and inequity for 8 maternal and newborn health care indicators in parts of rural Nigeria, Ethiopia and India.
\end{abstract}

METHODS: We examined coverage changes and inequity in 2012 and 2015 in 3 high-burden populations where multiple actors were attempting to improve outcomes. We conducted cluster-based household surveys using a structured questionnaire to collect 8 priority indicators, disaggregated by relative house- hold socioeconomic status. Where there was evidence of a change in coverage between 2012 and 2015, we used binomial regression models to assess whether the change reduced inequity.

RESULTS: In 2015, we interviewed women with a birth in the previous 12 months in Gombe, Nigeria ( $n=1100$ women), Ethiopia ( $n=404)$ and Uttar Pradesh, India ( $n=584)$. Among the 8 indicators, 2 positive coverage changes were observed in each of Gombe and Uttar Pradesh, and 5 in Ethiopia. Coverage improvements occurred equally for all socioeconomic groups, with little improvement in inequity. For example, in Ethiopia, coverage of facility delivery almost tripled, increasing from $15 \%$ (95\% confidence interval [Cl] $9 \%-25 \%)$ to $43 \%(95 \% \mathrm{Cl} 33 \%-54 \%)$. This change was similar across socioeconomic groups $(p=0.2)$. By 2015 , the poorest women had about the same facility delivery coverage as the least poor women had had in 2012 (32\% and $36 \%$, respectively), but coverage for the least poor had increased to $60 \%$.

INTERPRETATION: Although coverage increased equitably because of various community-based interventions, underlying inequities persisted. Action is needed to address the needs of the most vulnerable women, particularly those living in the most rural areas. n September 2015, the United Nations Member States adopted
the Sustainable Development Goals, a set of 17 goals for which
the target date for achievement is 2030 (https://sustainable
development.un.org/). The health agenda has a central place in
these goals, which aim to be relevant to all countries and to meet
the needs of women, children and the poorest, most disadvan-
taged people of the world. Despite important gains in maternal
and newborn health, faster progress is needed in many countries
to meet the Sustainable Development Goals for improved sur-
vival. ${ }^{1,2}$ More families need access to better-quality care across
the continuum from pregnancy to newborn periods, so that no
opportunity is lost to improve outcomes, including for those who
are most vulnerable. ${ }^{3,4}$ Addressing inequities in access to and
quality of health care is a priority now more than ever, as the
poorest members of communities continue to bear the largest
burden of ill health and consistently receive lower-quality care. ${ }^{5,6}$
Recognizing this situation, health programmers in low- and
middle-income countries have, over the past decade, aimed to implement strategies that favour the poorest members of communities and promote community linkages within primary health care. ${ }^{7-10}$ Certain interventions, such as training community members to make health promotion visits to families, have improved the practice of healthy behaviours in communities and increased care-seeking in health facilities. ${ }^{11,12}$

In 2012, in regions across Nigeria, Ethiopia and India, the implementation of community-based programming was prioritized. The aim of these programs was to improve maternal and newborn health outcomes through multiple approaches applied simultaneously by government, working alongside nongovernment organizations.

Here, we quantify the coverage and coverage change of 8 predefined essential maternal and newborn health indicators in these 3 regions. We assessed whether the community-based programming was associated with changes in outcomes, whether the changes observed were equitable and whether health care improved for the most vulnerable members of the population. 
Table 1: Indicators of maternal and newborn health targeted for change in all 3 jurisdictions*

\section{Denominator}

Indicator name

Indicators of access to essential care

1. Antenatal care

( $\geq 4$ visits)

2. Facility delivery

3. Postnatal care for mother $(\leq 48 \mathrm{~h})$

4. Postnatal care for newborn ( $\leq 48 \mathrm{~h}$ )

\section{Interventions or behaviours recommended for all families}

5. Birth attendant's use of gloves

6. Hygienic cord care previous 12 mo who reported that the delivery attendant wore gloves during the delivery

No. of last live births in the previous 12 mo who received clean cord care, defined as cord cut with a sterile blade, tied with a clean tie and nothing harmful put on the cord

7. Breastfeeding initiation $<1 \mathrm{~h}$

No. of last live births in the previous 12 mo who were first put to the breast within $1 \mathrm{~h}$ after birth

8. Delayed bathing $(>24 \mathrm{~h})$

of mothers aged 15-49 yr with a live birth in the 4 times while pregnant (any provider) a health facility

No. of mors aged 15-49y with a live birth in the
No. of last live births in the previous 12 mo who were not bathed in the first day of life check within $2 \mathrm{~d}$ after the delivery

*Data were collected for women 13-49 years of age; however, no women 13 or 14 years of age reported a live birth in the 12 months before the survey.

\section{Methods}

\section{Study setting}

The study took place in 2012 and 2015 in Gombe State, Nigeria; in the 4 most populous regions of Ethiopia; and in the state of Uttar Pradesh, India. We focused on these 3 diverse settings because they reflect areas of interest of the Bill \& Melinda Gates Foundation, a global health funder, and because they represent rural, poor populations experiencing a high number of maternal and neonatal deaths. ${ }^{13}$

Gombe State in northeast Nigeria has a population of 3.1 million. In 2015, the state had an estimated maternal mortality ratio of 1549 per 100000 population and a neonatal mortality rate of 35 per 1000 population. ${ }^{14}$ In Ethiopia, the implementation area covered a population of about 6 million people living in 59 districts in the 4 regions of Oromia, Tigray, Amhara and Southern Nations Nationalities and Peoples. In 2015, the country had an estimated maternal mortality ratio of 353 per 100000 population and a neonatal mortality rate of 28 per 1000 population..$^{15}$ In Uttar Pradesh, implementation took place within a population of about 13 million people living in 6 districts. In 2016, the maternal mortality ratio in this state was estimated at 201 per 100000 population and the neonatal mortality rate at 35 per 1000 population. ${ }^{16}$

The prioritization process for what was to be implemented in each study setting involved consultation with government and community leaders and was guided by a global recommendation concerning the basic package of care for all women and newborns, emphasizing a core set of interventions that could be delivered at the community or primary health level. ${ }^{17}$ Following detailed characterization of the individual implementation approaches, ${ }^{18} 8$ indicators for improvement were identified across the study areas: 4 for access to essential care and 4 for interventions or behaviours recommended for all families (Table 1).

Community-based programming differed according to setting; however, all interventions were designed to improve survival, to reach the poor, to be feasible for large-scale implementation and to support government priorities (Box 1). For example, the interventions included an emergency transport scheme to remove access barriers in Gombe, improved use of local data to identify families in need of care in Ethiopia and the establishment of women's groups in Uttar Pradesh. For further detail, see Appendix 1 (available at www.cmaj.ca/lookup/suppl/ doi:10.1503/cmaj.190219/-/DC1).

\section{Survey overview}

We performed cluster-based household surveys in 2012 and 2015, which involved interviewing women who reported a live birth in the preceding 12 months. ${ }^{19,20}$ The same methods and sampling frames were applied in both years and covered the entire area of implementation (Appendix 1). 
Box 1: Illustrative components of community-based programming

\section{Gombe State, Nigeria*}

- Train and deploy female community volunteers to make home visits to families to promote healthy maternal and newborn care practices; equip volunteers with clean delivery kits

- Initiate a call centre, with toll-free numbers, to offer free health advice to families

- Initiate an emergency transport scheme whereby community members with vehicles are trained in a transportation protocol for women who need urgent care in a health facility

- Conduct limited upgrading of primary health facilities

Ethiopia†

- Facilitate community-based data for decision-making, helping community health workers and volunteers to work together to identify families in need of care; this activity was fully integrated within the government's health strategy of deploying health extension workers and a Health Development Army

- Provide nonfinancial incentives for the Health Development Army

- Provide supplemental training to the Health Development Army

- Strengthen partnerships between community actors and primary health facility structures

\section{Uttar Pradesh, Indiał}

- Expand community-based women's self-help groups to include maternal and newborn care topics

- Strengthen linkages between self-help groups and health facility structures

- Develop and deploy a mobile phone app as a job aid to support the work of community health workers

- Initiate a mother and child tracking system to facilitate recordkeeping and tracking of care provision for individual families

*For further detail, see the Maternal and Neonatal Health Project - Gombe (http://www.sfhnigeria.org/the-maternal-and-neonatal-health-project-2012 $-2016 /)$.

†For further detail, see the Last Ten Kilometers Project (http://L10k.jsi.com/)

$\ddagger$ For further detail, see the RGMVP (Rajiv Gandhi Mahila Vikas Pariyojana), a poverty reduction program of the Rajiv Gandhi Charitable Trust (http://www.rgmvp.org/).

We applied multistage random sampling to generate a representative sample of women living in the implementation areas. In Gombe State, clusters were defined as enumeration areas. The enumeration areas were listed alphabetically, and their population size cumulated; areas were then systematically selected with probability proportional to population size. Households in the selected enumeration areas were listed and enumeration areas segmented into groups of about 75 households, with 1 segment in each enumeration area randomly selected for the survey.

In Ethiopia, clusters were defined as villages. The 59 implementation districts (woreda) and their subdistricts (kebele) were listed geographically from north to south, and their population size cumulated; subdistricts were then systematically selected with probability proportional to population size. One village was randomly sampled for each selected subdistrict. Within each village, households were listed and villages segmented into groups of about 75 households, with 1 segment in each village randomly selected for the survey.
In Uttar Pradesh, clusters were defined as villages. All villages from the 6 implementation districts were listed alphabetically, and their population size cumulated; villages were then systematically selected with probability proportional to population size. All households within selected villages were listed and villages segmented into groups of about 75 households, with 1 segment in each village randomly selected for the survey.

The final sample size was sufficient to measure, with $90 \%$ power and a $5 \%$ level of significance, changes of a minimum of 20 percentage points across the range of indicators, representing the magnitude of change that was anticipated by project partners. In 2015, partly because of declining trends in fertility, 2 changes were made to increase the sample size. In Gombe, the number of clusters was doubled, and in all 3 jurisdictions, cluster size was increased from 50 to 75 households (Table 2).

A modular household questionnaire was applied by trained interviewers. In 2012, there was relatively little guidance available on best practice for measurement of maternal and newborn health. ${ }^{21}$ We conducted extensive pretesting of questions and pilot testing of survey protocols, and we reviewed existing surveys, including the Demographic and Health Survey. ${ }^{22}$ In brief, household heads were asked about socioeconomic characteristics, and resident women aged 13-49 years were asked about their access to health care in the past year. Further questions were asked of women who reported a recent birth. As an example, the questionnaire implemented in Ethiopia in 2015 is provided in English in Appendix 2 (available at www.cmaj.ca/ lookup/suppl/doi:10.1503/cmaj.190219/-/DC1).

After translation and back-translation, surveys were implemented in Hausa in Gombe; in Amharic, Oromifa and Tigrinya in Ethiopia; and in Hindi in Uttar Pradesh. In Gombe and Uttar Pradesh, the data were collected using hand-held digital devices. In Ethiopia, the data were collected in 2012 using paper questionnaires, which were double-entered and reconciled; digital data collection was introduced in 2015. To enhance response rates, survey teams revisited each household up to 3 times for call-backs. Informed, written consent was obtained from all participants.

\section{Statistical analysis}

We performed the analyses separately for each study setting. We adjusted coverage indicators for clustering of the segmented villages using the svy command in Stata 14 (StataCorp). We calculated odds ratios (ORs) for the difference in coverage over time using individual-level binomial regression models.

For each survey, we used principal components analysis to construct an indicator of relative household socioeconomic status. We divided the resulting continuous index variable into quintiles of households from quintile 1 (poorest) to quintile 5 (least poor). The characteristics of poorest and least poor families in the 3 jurisdictions are illustrated in Appendix 3 (available at www.cmaj.ca/lookup/suppl/doi:10.1503/cmaj.190219/-/DC1).

We examined the association between household socioeconomic status quintile and indicator coverage at each time point using binomial regression. We tested linearity of the association between socioeconomic status and indicators using a likelihood ratio test, comparing a model with socioeconomic status 
Table 2: Household survey samples in 2012 and 2015

\begin{tabular}{|c|c|c|c|c|c|c|}
\hline \multirow[b]{2}{*}{ Sample characteristic } & \multicolumn{2}{|c|}{ Gombe State, Nigeria* } & \multicolumn{2}{|c|}{ Ethiopia† } & \multicolumn{2}{|c|}{ Uttar Pradesh, Indiał } \\
\hline & 2012 & 2015 & 2012 & 2015 & 2012 & 2015 \\
\hline No. of clusters & 40 & 80 & 40 & 40 & 80 & 80 \\
\hline \multicolumn{7}{|l|}{ Households } \\
\hline Target no. to be surveyed§ & 2000 & 6000 & 2000 & 3000 & 6000 & 6000 \\
\hline No. surveyed & 1844 & 5939 & 2118 & 3000 & 5258 & 6466 \\
\hline Response rate, $\%$ & 92 & 99 & 106 & 100 & 88 & 108 \\
\hline \multicolumn{7}{|l|}{ Resident women } \\
\hline No. of women age $13-49 \mathrm{yr}$ listed & 2718 & 8125 & 2153 & 3480 & 8641 & 9446 \\
\hline No. interviewed & 2021 & 7419 & 1934 & 3170 & 8120 & 8522 \\
\hline Response rate, \% & $74^{\star *}$ & 91 & 90 & 91 & 94 & 90 \\
\hline With birth in 12 mo preceding survey 9 & 349 & 1100 & 277 & 404 & 604 & 584 \\
\hline \multicolumn{7}{|c|}{ 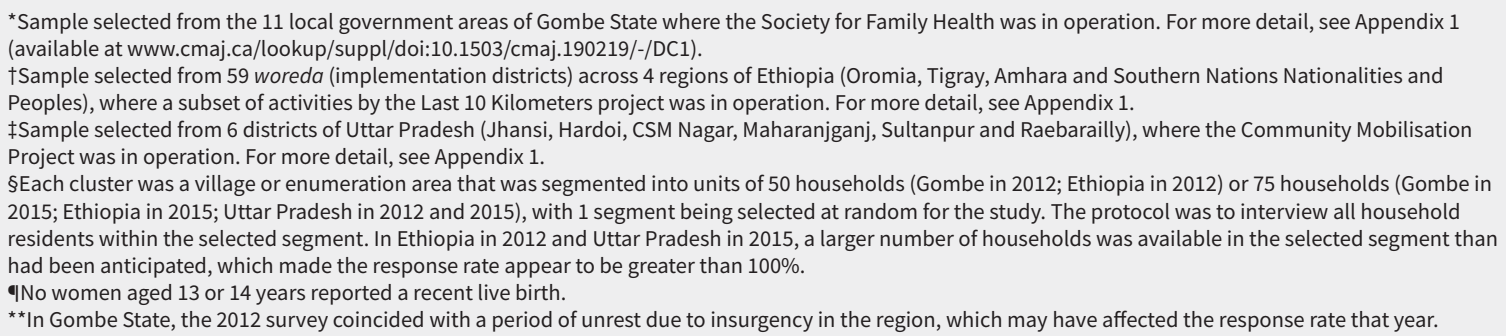 } \\
\hline
\end{tabular}

quintiles treated as a continuous variable with a model in which quintiles were treated as categories. Where there was no evidence of nonlinearity, we calculated the ORs and 95\% confidence intervals (Cls) for a 1-unit change in socioeconomic status. Where there was evidence of nonlinearity, we calculated separate ORs for each socioeconomic status quintile. Where there was evidence of coverage change between survey years, to determine whether the association between household socioeconomic status quintile and indicator coverage changed over time, we included data from both time points in a binomial regression model and tested for an interaction between time point and socioeconomic status quintile. All regression models were at the individual-woman level and included robust standard errors to account for clustering of the data. We used interaction tests to examine whether change was inequitable for multiple indicators. A $p$ value of less than 0.05 was used to indicate statistical significance.

\section{Ethics approval}

In Nigeria, national-level approval was obtained from the National Health Research Ethics Committee, Federal Ministry of Health, Abuja, and in Gombe State from the State Ministry of Health in both Gombe and Abuja. In Ethiopia, national-level support was obtained from the Ethiopian Ministry of Health and ethics approval from the Ministry of Science and Technology; at the regional level, approval was granted by the Regional Institutional Review Boards in Oromia, Tigray, Amhara, and Southern Nations Nationalities and Peoples. In Uttar Pradesh, India, approval was obtained from SPECT-ERB, an independent ethics review board, and written permission was obtained from the
National Rural Health Mission of Uttar Pradesh. Ethics approval was also obtained from the London School of Hygiene \& Tropical Medicine (reference 6088).

\section{Results}

\section{Gombe State, Nigeria}

In Gombe State, 74\% (2021/2718) of all women residing in sampled households were interviewed about their recent fertility history in 2012, and $91 \%(7419 / 8125)$ in 2015 . Of these, $17 \%$ $(349 / 2021)$ in 2012 and 15\% (1100/7419) in 2015 reported a recent live birth (Table 2). There was no evidence of a difference in demographic characteristics between survey years. In 2012, the women interviewed had a mean age of 26 years, 93\% were currently married, $66 \%$ had no formal education, $83 \%$ were Muslim, and $17 \%$ were Christian (Table 3 ).

All access and care indicators had coverage below $50 \%$ in both years (Table 4). In 2012, 40\% (139/348; 95\% Cl 30\%-51\%) of women had at least 4 antenatal care visits, and 30\% (104/348; $95 \% \mathrm{Cl} 21 \%-41 \%$ ) had a facility delivery, but very few women or newborns had timely postnatal care. Large-scale inequities were present for all indicators of access to care.

By 2015, coverage had increased for 2 intervention indicators: hygienic cord care from 26\% (92/348; 95\% Cl 19\%-36\%) in 2012 to $45 \%(490 / 1100 ; 95 \% \mathrm{Cl} 41 \%-49 \%)$ in 2015 , and breastfeeding initiation within 1 hour after birth increased from 40\% (135/340; $95 \% \mathrm{Cl} 33 \%-47 \%)$ in 2012 to $49 \%$ (533/1081; 95\% Cl 46\%-53\%) in 2015. All socioeconomic status quintiles benefited equally from this positive coverage change ( $p$ values for interaction between time and socioeconomic status 0.1 and 0.3 , respectively). 
Country; year; no. (\%) of respondents†

\begin{tabular}{|c|c|c|c|c|c|c|}
\hline \multirow[b]{2}{*}{ Characteristic } & \multicolumn{2}{|c|}{ Gombe State } & \multicolumn{2}{|c|}{ Ethiopia } & \multicolumn{2}{|c|}{ Uttar Pradesh } \\
\hline & $\begin{array}{c}2012 \\
n=349\end{array}$ & $\begin{array}{c}2015 \\
n=1100\end{array}$ & $\begin{array}{c}2012 \\
n=277\end{array}$ & $\begin{array}{c}2015 \\
n=404\end{array}$ & $\begin{array}{c}2012 \\
n=604\end{array}$ & $\begin{array}{c}2015 \\
n=584\end{array}$ \\
\hline Age, yr, mean & 26 & 26 & 26 & 27 & 26 & 26 \\
\hline Currently married & $324(93)$ & 1067 (97) & $265(96)$ & $392(97)$ & $604(100)$ & $578(99)$ \\
\hline \multicolumn{7}{|l|}{ Education level } \\
\hline None & $230(66)$ & $759(69)$ & $169(61)$ & $218(54)$ & $242(40)$ & $228(39)$ \\
\hline Primary & $60(17)$ & $143(13)$ & $85(31)$ & $133(33)$ & $133(22)$ & $99(17)$ \\
\hline Secondary & $59(17)$ & $198(18)$ & $23(8)$ & $53(13)$ & $229(38)$ & $257(44)$ \\
\hline \multicolumn{7}{|l|}{ Religion } \\
\hline Christian & $60(17)$ & $143(13)$ & $185(67)$ & $286(71)$ & $0(0)$ & $0(0)$ \\
\hline Muslim & $289(83)$ & $957(87)$ & $92(33)$ & $118(29)$ & $42(7)$ & $58(10)$ \\
\hline Hindu & $0(0)$ & $0(0)$ & $0(0)$ & $0(0)$ & $562(93)$ & $526(90)$ \\
\hline \multicolumn{7}{|c|}{$\begin{array}{l}\text { Household socioeconomic } \\
\text { status, by quintile }\end{array}$} \\
\hline Q1 (poorest) & $73(21)$ & $165(15)$ & $60(22)$ & $82(20)$ & $127(21)$ & $106(18)$ \\
\hline Q2 & $45(13)$ & $220(20)$ & $59(21)$ & $74(18)$ & $109(18)$ & $128(22)$ \\
\hline Q3 & $76(22)$ & $255(23)$ & $53(19)$ & $76(19)$ & $97(16)$ & $97(17)$ \\
\hline Q4 & $74(21)$ & $251(23)$ & $53(19)$ & $84(21)$ & $145(24)$ & $124(21)$ \\
\hline Q5 (least poor) & $81(23)$ & 209 (19) & $52(19)$ & $88(22)$ & $126(21)$ & $129(22)$ \\
\hline
\end{tabular}

*Despite small differences in the point estimates, within each geographic area there was no evidence of a statistically significant difference in the characteristics of women by survey year. For example, in Ethiopia, the percentage of women with a recent live birth who reported having no formal education was smaller in 2015 than in 2012 , but the confidence intervals (Cls) overlapped (61\% [95\% Cl 52\%-70\%] in 2012 v. 54\% [95\% Cl 47\%-62\%] in 2015).

tExcept where indicated otherwise.

\section{Four regions of Ethiopia}

In Ethiopia, in both 2012 and 2015, about 90\% of resident women were interviewed. Of these, $14 \%(277 / 1934)$ in 2012 and $13 \%$ (404/3170) in 2015 reported a recent live birth (Table 2). There was no evidence of a difference in demographic characteristics between survey years. In 2012, the women interviewed had a mean age of 26 years, $96 \%$ were currently married, $61 \%$ had no formal education, $67 \%$ were Christian, and $33 \%$ were Muslim (Table 3 ).

In 2012, no intervention indicator had coverage higher than $50 \%$, and no indicator of access to care had coverage higher than $25 \%$, being lowest for newborn postnatal care $(4 \%$ [10/277], 95\% Cl 2\%-7\%) (Table 5). Coverage inequity in relation to socioeconomic status was present in 2012 for facility delivery $(p=0.001)$ and birth attendant's use of gloves $(p<0.001)$.

By 2015, some large-scale changes had occurred for both access and intervention indicators. Coverage of at least 4 antenatal visits almost doubled, from $22 \%(62 / 277 ; 95 \% \mathrm{Cl} 14 \%-34 \%)$ to $39 \%$ (156/404; $95 \% \mathrm{Cl} 30 \%-48 \%$ ), although coverage in 2015 for the poorest women was equivalent to coverage in 2012 for the least poor women (35\% and $31 \%$, respectively). Facility delivery almost tripled from $15 \%(41 / 277 ; 95 \% \mathrm{Cl} 9 \%-25 \%)$ in 2012 to $43 \%$ (172/404; 95\% Cl 33\%-54\%) in 2015, although 2015 coverage for the poorest women was equivalent to 2012 coverage for the least poor women (32\% and 36\%, respectively). Delayed bathing increased from $39 \%(107 / 274 ; 95 \% \mathrm{Cl} 30 \%-49 \%)$ to $50 \%$
(204/404; 95\% Cl 41\%-60\%), with 2015 coverage for the poorest women approaching 2012 coverage for the least poor women (42\% and $48 \%$, respectively). Breastfeeding initiation within 1 hour increased from $50 \%(136 / 274 ; 95 \% \mathrm{Cl} 42 \%-58 \%)$ to $66 \%$ (264/400; $95 \% \mathrm{Cl} 59 \%-72 \%)$ with no evidence of inequity in either year. Birth attendant's use of gloves doubled in coverage, from $26 \%(61 / 239$; $95 \% \mathrm{Cl} 17 \%-37 \%)$ in 2012 to $54 \%(192 / 357$; $95 \% \mathrm{Cl} 43 \%-64 \%$ ) in 2015, with evidence of the greatest increase for the poorest women ( $p$ value for interaction 0.03 ; Table 5 ).

\section{Six districts of Uttar Pradesh, India}

In Uttar Pradesh, 94\% (8120/8641) of all resident women were interviewed in 2012, and 90\% (8522/9446) in 2015. Of these, $7 \%$ (604/8120) in 2012 and 7\% (584/8522) in 2015 reported a recent live birth (Table 2). There was no evidence of a difference in demographic characteristics between survey years. In 2012, the women had a mean age of 26 years, $100 \%$ were currently married, $40 \%$ had no formal education, $93 \%$ were Hindu, and $7 \%$ were Muslim (Table 3).

In 2012, coverage levels were all about $50 \%$ or above, with the exception of at least 4 antenatal visits $(28 \%$ [170/604]; $95 \% \mathrm{Cl}$ $24 \%-33 \%)$ and postnatal care for the newborn (19\% [114/604]; 95\% Cl 15\%-23\%); these 2 indicators still had the lowest coverage in 2015 (Table 6). Evidence of inequity in relation to socioeconomic status was present in 2012 for antenatal care $(p<$ 
Table 4: Evidence of coverage change between 2012 and 2015, overall and by socioeconomic status, for targeted maternal

and newborn health indicators in Gombe State, Nigeria

\begin{tabular}{|c|c|c|c|c|c|c|c|c|c|}
\hline \multirow[b]{2}{*}{ Indicator } & \multicolumn{2}{|c|}{$\begin{array}{c}\text { Year; } \\
\% \text { coverage }(95 \% \mathrm{Cl})\end{array}$} & \multirow{2}{*}{$\begin{array}{c}\text { Coverage } \\
\text { change } \\
p \text { value } \\
\text { for OR* }\end{array}$} & \multirow[b]{2}{*}{$\begin{array}{c}\text { SES } \\
\text { quintile† }\end{array}$} & \multicolumn{2}{|c|}{$\begin{array}{l}\text { Coverage by SES } \\
\text { in } 2012\end{array}$} & \multicolumn{2}{|c|}{$\begin{array}{l}\text { Coverage by SES } \\
\text { in } 2015\end{array}$} & \multirow{2}{*}{$\begin{array}{c}\begin{array}{c}\text { Time-SES } \\
\text { interaction }\end{array} \\
\begin{array}{c}p \text { value for } \\
\text { interaction } \S\end{array}\end{array}$} \\
\hline & $\begin{array}{c}2012 \\
n=349\end{array}$ & $\begin{array}{c}2015 \\
n=1100\end{array}$ & & & $\begin{array}{c}\% \text { coverage } \\
(95 \% \mathrm{Cl})\end{array}$ & $\begin{array}{l}p \text { value } \\
\text { for OR }\end{array}$ & $\begin{array}{l}\% \text { coverage } \\
(95 \% \mathrm{CI})\end{array}$ & $\begin{array}{l}p \text { value } \\
\text { for OR } \neq\end{array}$ & \\
\hline \multirow[t]{5}{*}{ Antenatal care } & $40(30-51)$ & $37(30-43)$ & 0.5 & Q1 & $18(8-33)$ & \multirow{5}{*}{$<0.001$} & $28(20-39)$ & \multirow{5}{*}{$<0.001$} & \multirow{5}{*}{-} \\
\hline & & & & Q2 & $26(14-43)$ & & $24(16-34)$ & & \\
\hline & & & & Q3 & $39(25-56)$ & & $28(22-35)$ & & \\
\hline & & & & Q4 & $45(32-58)$ & & $44(34-54)$ & & \\
\hline & & & & Q5 & $65(55-74)$ & & $57(46-68)$ & & \\
\hline \multirow[t]{5}{*}{ Facility delivery } & $30(21-41)$ & $29(24-35)$ & 0.8 & Q1 & $9(4-19)$ & \multirow{5}{*}{$<0.001$} & $17(11-25)$ & \multirow{5}{*}{$<0.001$} & \multirow{5}{*}{-} \\
\hline & & & & Q2 & $20(9-37)$ & & $17(12-25)$ & & \\
\hline & & & & Q3 & $22(9-43)$ & & $19(13-27)$ & & \\
\hline & & & & Q4 & $36(26-48)$ & & $31(24-40)$ & & \\
\hline & & & & Q5 & $56(41-70)$ & & $61(53-69)$ & & \\
\hline \multirow[t]{5}{*}{ Postnatal care for mother } & $7(4-10)$ & $10(7-13)$ & 0.1 & Q1 & 0 & \multirow{5}{*}{0.02} & $7(3-14)$ & \multirow{5}{*}{0.02} & \multirow{5}{*}{-} \\
\hline & & & & Q2 & $7(2-17)$ & & $7(3-13)$ & & \\
\hline & & & & Q3 & $8(4-16)$ & & $8(5-13)$ & & \\
\hline & & & & Q4 & $15(8-26)$ & & $11(7-18)$ & & \\
\hline & & & & Q5 & $4(1-15)$ & & $15(10-22)$ & & \\
\hline \multirow[t]{5}{*}{ Postnatal care for newborn } & $4(2-9)$ & $7(5-10)$ & 0.18 & Q1 & 0 & \multirow{5}{*}{$<0.001$} & $5(2-9)$ & \multirow{5}{*}{0.3} & \multirow{5}{*}{-} \\
\hline & & & & Q2 & 0 & & $7(4-13)$ & & \\
\hline & & & & Q3 & $3(1-10)$ & & $7(4-14)$ & & \\
\hline & & & & Q4 & $9(4-22)$ & & $6(4-11)$ & & \\
\hline & & & & Q5 & $6(2-17)$ & & $9(5-15)$ & & \\
\hline Attendant use of gloves & $46(34-58)$ & $44(38-51)$ & 0.82 & Q1 & $21(12-33)$ & & $31(22-42)$ & & \\
\hline & & & & Q2 & $22(10-44)$ & & $31(22-41)$ & & \\
\hline & & & & Q3 & $42(25-62)$ & $<0.001$ & $33(25-41)$ & $<0.001$ & - \\
\hline & & & & Q4 & $47(32-63)$ & & $49(40-58)$ & & \\
\hline & & & & Q5 & $77(62-88)$ & & $77(68-84)$ & & \\
\hline Hygienic cord care & $26(19-36)$ & $45(41-49)$ & $<0.004$ & Q1 & $36(21-55)$ & & $36(27-45)$ & & \\
\hline & & & & Q2 & $20(9-38)$ & & $43(35-51)$ & & \\
\hline & & & & Q3 & $26(15-41)$ & 0.4 & $49(41-57)$ & 0.1 & 0.1 \\
\hline & & & & Q4 & $19(9-35)$ & & $45(37-53)$ & & \\
\hline & & & & Q5 & $29(16-46)$ & & $48(38-59)$ & & \\
\hline Breastfeeding initiation & $40(33-47)$ & $49(46-53)$ & 0.01 & Q1 & $25(15-39)$ & & $46(38-55)$ & & \\
\hline & & & & Q2 & $43(26-62)$ & & $52(44-60)$ & & \\
\hline & & & & Q3 & $39(24-56)$ & 0.02 & $47(40-54)$ & 0.7 & 0.3 \\
\hline & & & & Q4 & $46(34-59)$ & & $51(43-58)$ & & \\
\hline & & & & Q5 & $46(34-59)$ & & $50(42-58)$ & & \\
\hline Delayed bathing & $15(10-21)$ & $21(17-26)$ & 0.07 & Q1 & $11(5-23)$ & & $21(13-31)$ & & \\
\hline & & & & Q2 & $7(1-25)$ & & $20(14-28)$ & & \\
\hline & & & & Q3 & $19(8-39)$ & 0.2 & $17(12-24)$ & 0.2 & - \\
\hline & & & & Q4 & $18(9-30)$ & & $22(17-28)$ & & \\
\hline & & & & Q5 & $16(10-26)$ & & $28(20-37)$ & & \\
\hline
\end{tabular}


Table 5: Evidence of coverage change between 2012 and 2015, overall and by socioeconomic status, for targeted maternal

and newborn health indicators in Ethiopia

\begin{tabular}{|c|c|c|c|c|c|c|c|c|c|}
\hline \multirow[b]{2}{*}{ Indicator } & \multicolumn{2}{|c|}{$\begin{array}{c}\text { Year; } \\
\% \text { coverage }(95 \% \mathrm{Cl})\end{array}$} & \multirow{2}{*}{$\begin{array}{c}\text { Coverage } \\
\text { change } \\
p \text { value } \\
\text { for OR* }\end{array}$} & \multirow[b]{2}{*}{$\begin{array}{c}\text { SES } \\
\text { quintile† }\end{array}$} & \multicolumn{2}{|c|}{$\begin{array}{l}\text { Coverage by SES } \\
\text { in } 2012\end{array}$} & \multicolumn{2}{|c|}{$\begin{array}{c}\text { Coverage by SES } \\
\text { in } 2015\end{array}$} & \multirow{2}{*}{$\begin{array}{c}\text { Time-SES } \\
\text { interaction } \\
\text { p value for } \\
\text { interaction } \S\end{array}$} \\
\hline & $\begin{array}{c}2012 \\
n=277\end{array}$ & $\begin{array}{c}2015 \\
n=404\end{array}$ & & & $\begin{array}{c}\text { \% coverage } \\
(95 \% \mathrm{CI})\end{array}$ & $\begin{array}{l}p \text { value } \\
\text { for OR }\end{array}$ & $\begin{array}{c}\% \text { coverage } \\
(95 \% \mathrm{CI})\end{array}$ & $\begin{array}{l}p \text { value } \\
\text { for OR } ¥\end{array}$ & \\
\hline \multirow[t]{5}{*}{ Antenatal care } & $22(14-34)$ & $39(30-48)$ & $<0.002$ & Q1 & $16(9-27)$ & \multirow{5}{*}{0.06} & $35(23-50)$ & \multirow{5}{*}{0.01} & \multirow{5}{*}{0.9} \\
\hline & & & & Q2 & $21(8-42)$ & & $29(17-45)$ & & \\
\hline & & & & Q3 & $15(7-29)$ & & $28(17-43)$ & & \\
\hline & & & & Q4 & $30(18-45)$ & & $46(35-57)$ & & \\
\hline & & & & Q5 & $31(18-48)$ & & $54(41-65)$ & & \\
\hline \multirow[t]{5}{*}{ Facility delivery } & $15(9-25)$ & $43(33-54)$ & $<0.001$ & Q1 & $5(1-16)$ & \multirow{5}{*}{0.001} & $32(22-46)$ & \multirow{5}{*}{0.01} & \multirow{5}{*}{0.2} \\
\hline & & & & Q2 & $9(3-22)$ & & $37(23-54)$ & & \\
\hline & & & & Q3 & $11(5-24)$ & & $29(18-43)$ & & \\
\hline & & & & Q4 & $17(7-36)$ & & $53(37-69)$ & & \\
\hline & & & & Q5 & $36(21-52)$ & & $60(43-78)$ & & \\
\hline \multirow[t]{5}{*}{ Postnatal care for mother } & $4(2-8)$ & $4(2-6)$ & 0.7 & Q1 & $5(2-14)$ & \multirow{5}{*}{0.6} & $4(1-12)$ & \multirow{5}{*}{0.2} & \multirow{5}{*}{-} \\
\hline & & & & Q2 & $2(0-12)$ & & 0 & & \\
\hline & & & & Q3 & $4(1-15)$ & & $2(1-10)$ & & \\
\hline & & & & Q4 & $2(0-13)$ & & $5(2-12)$ & & \\
\hline & & & & Q5 & $8(2-23)$ & & $6(2-15)$ & & \\
\hline \multirow[t]{5}{*}{ Postnatal care for newborn } & $4(2-7)$ & $4(2-7)$ & 0.7 & Q1 & $2(0-10)$ & \multirow{5}{*}{0.05} & $5(2-13)$ & \multirow{5}{*}{0.2} & \multirow{5}{*}{-} \\
\hline & & & & Q2 & 0 & & 0 & & \\
\hline & & & & Q3 & $6(2-17)$ & & $1(0-9)$ & & \\
\hline & & & & Q4 & $4(1-15)$ & & $7(4-14)$ & & \\
\hline & & & & Q5 & $8(3-20)$ & & $7(2-20)$ & & \\
\hline Attendant use of gloves & $26(17-37)$ & $54(43-64)$ & $<0.001$ & Q1 & $6(2-19)$ & & $48(33-62)$ & & \\
\hline & & & & Q2 & $27(15-42)$ & & $47(32-63)$ & & \\
\hline & & & & Q3 & $22(11-38)$ & $<0.001$ & $42(28-57)$ & 0.03 & 0.03 \\
\hline & & & & Q4 & $25(12-44)$ & & $59(46-72)$ & & \\
\hline & & & & Q5 & $50(36-64)$ & & $71(53-84)$ & & \\
\hline Hygienic cord care & $44(36-52)$ & $51(41-60)$ & 0.2 & Q1 & $34(23-49)$ & & $53(37-68)$ & & \\
\hline & & & & Q2 & $38(9-49)$ & & $47(34-61)$ & & \\
\hline & & & & Q3 & $49(33-65)$ & 0.08 & $55(41-68)$ & 0.9 & - \\
\hline & & & & Q4 & $54(39-68)$ & & $46(31-61)$ & & \\
\hline & & & & Q5 & $45(31-60)$ & & $52(37-67)$ & & \\
\hline Breastfeeding initiation & $50(42-58)$ & $66(59-72)$ & $<0.001$ & Q1 & $48(33-64)$ & & $71(58-81)$ & & \\
\hline & & & & Q2 & $47(34-61)$ & & $66(53-77)$ & & \\
\hline & & & & Q3 & $51(33-69)$ & 0.9 & $62(50-73)$ & 0.7 & 0.3 \\
\hline & & & & Q4 & $59(45-72)$ & & $64(51-75)$ & & \\
\hline & & & & Q5 & $42(28-57)$ & & $68(54-79)$ & & \\
\hline Delayed bathing & $39(30-49)$ & $50(41-60)$ & 0.03 & Q1 & $28(17-42)$ & & $42(31-54)$ & & \\
\hline & & & & Q2 & $41(26-59)$ & & $38(27-51)$ & & \\
\hline & & & & Q3 & $35(21-53)$ & 0.05 & $42(29-56)$ & $<0.001$ & 0.3 \\
\hline & & & & Q4 & $44(29-61)$ & & $59(46-71)$ & & \\
\hline & & & & Q5 & $48(35-61)$ & & $70(54-82)$ & & \\
\hline
\end{tabular}


Table 6: Evidence of coverage change between 2012 and 2015, overall and by socioeconomic status, for targeted maternal

and newborn health indicators in Uttar Pradesh, India

\begin{tabular}{|c|c|c|c|c|c|c|c|c|c|}
\hline \multirow[b]{2}{*}{ Indicator } & \multicolumn{2}{|c|}{$\begin{array}{c}\text { Year; } \\
\% \text { coverage }(95 \% \mathrm{Cl})\end{array}$} & \multirow{2}{*}{$\begin{array}{c}\begin{array}{c}\text { Coverage } \\
\text { change }\end{array} \\
\begin{array}{c}p \text { value for } \\
\text { OR }^{\star}\end{array}\end{array}$} & \multirow[b]{2}{*}{$\begin{array}{c}\text { SES } \\
\text { quintile† }\end{array}$} & \multicolumn{2}{|c|}{$\begin{array}{l}\text { Coverage by SES } \\
\text { in } 2012\end{array}$} & \multicolumn{2}{|c|}{$\begin{array}{l}\text { Coverage by SES } \\
\text { in } 2015\end{array}$} & \multirow{2}{*}{$\begin{array}{c}\begin{array}{c}\text { Time-SES } \\
\text { interaction }\end{array} \\
\begin{array}{c}p \text { value for } \\
\text { interaction } \S\end{array}\end{array}$} \\
\hline & $\begin{array}{c}2012 \\
n=604\end{array}$ & $\begin{array}{c}2015 \\
n=584\end{array}$ & & & $\begin{array}{c}\% \text { coverage } \\
(95 \% \mathrm{CI})\end{array}$ & $\begin{array}{l}p \text { value } \\
\text { for OR }\end{array}$ & $\begin{array}{c}\% \text { coverage } \\
(95 \% \mathrm{CI})\end{array}$ & $\begin{array}{l}p \text { value } \\
\text { for OR } \neq\end{array}$ & \\
\hline \multirow[t]{5}{*}{ Antenatal care } & $28(24-33)$ & $25(21-30)$ & 0.3 & Q1 & $16(9-26)$ & \multirow{5}{*}{$<0.001$} & $20(13-30)$ & \multirow{5}{*}{0.09} & \multirow{5}{*}{-} \\
\hline & & & & Q2 & $25(17-34)$ & & $22(15-32)$ & & \\
\hline & & & & Q3 & $25(17-34)$ & & $24(15-35)$ & & \\
\hline & & & & Q4 & $27(21-35)$ & & $30(21-40)$ & & \\
\hline & & & & Q5 & $44(35-54)$ & & $29(21-39)$ & & \\
\hline \multirow[t]{5}{*}{ Facility delivery } & $76(71-80)$ & $81(77-85)$ & 0.03 & Q1 & $68(56-79)$ & \multirow{5}{*}{0.007} & $80(69-87)$ & \multirow{5}{*}{0.2} & \multirow{5}{*}{0.8} \\
\hline & & & & Q2 & $74(66-81)$ & & $79(71-85)$ & & \\
\hline & & & & Q3 & $73(64-80)$ & & $78(68-86)$ & & \\
\hline & & & & Q4 & $77(69-84)$ & & $84(76-90)$ & & \\
\hline & & & & Q5 & 85 (77-90) & & $85(76-90)$ & & \\
\hline \multirow[t]{5}{*}{ Postnatal care for mother } & $54(48-59)$ & $63(58-67)$ & 0.004 & Q1 & $49(37-62)$ & \multirow{5}{*}{0.1} & $64(53-75)$ & \multirow{5}{*}{0.3} & \multirow{5}{*}{0.4} \\
\hline & & & & Q2 & $50(40-61)$ & & $66(58-73)$ & & \\
\hline & & & & Q3 & $52(42-62)$ & & $58(49-68)$ & & \\
\hline & & & & Q4 & $54(45-63)$ & & $65(56-73)$ & & \\
\hline & & & & Q5 & $60(51-69)$ & & $58(50-66)$ & & \\
\hline \multirow[t]{5}{*}{ Postnatal care for newborn } & $19(15-23)$ & $15(11-20)$ & 0.2 & Q1 & $13(7-21)$ & \multirow{5}{*}{0.01} & $7(3-14)$ & \multirow{5}{*}{0.02} & \multirow{5}{*}{-} \\
\hline & & & & Q2 & $18(12-26)$ & & $21(15-29)$ & & \\
\hline & & & & Q3 & $16(11-24)$ & & $16(9-25)$ & & \\
\hline & & & & Q4 & $15(9-25)$ & & $14(8-23)$ & & \\
\hline & & & & Q5 & $30(22-39)$ & & $15(10-23)$ & & \\
\hline Attendant use of gloves & $85(82-88)$ & $88(85-91)$ & 0.1 & Q1 & $77(65-85)$ & & $86(77-92)$ & & \\
\hline & & & & Q2 & $85(78-90)$ & & $88(81-93)$ & & \\
\hline & & & & Q3 & $87(79-92)$ & 0.04 & $85(76-91)$ & 0.4 & - \\
\hline & & & & Q4 & $83(75-89)$ & & 89 (79-95) & & \\
\hline & & & & Q5 & $91(83-95)$ & & $90(83-94)$ & & \\
\hline Hygienic cord care & $49(44-53)$ & $53(48-57)$ & 0.19 & Q1 & $51(42-61)$ & & $58(48-67)$ & & \\
\hline & & & & Q2 & $50(41-58)$ & & $52(42-62)$ & & \\
\hline & & & & Q3 & $50(40-60)$ & 0.3 & $53(43-63)$ & 0.3 & - \\
\hline & & & & Q4 & $50(41-59)$ & & $55(48-63)$ & & \\
\hline & & & & Q5 & $44(36-53)$ & & $47(39-56)$ & & \\
\hline Breastfeeding initiation & $54(48-59)$ & $55(51-60)$ & 0.6 & Q1 & $55(44-65)$ & & $57(45-68)$ & & \\
\hline & & & & Q2 & $49(39-59)$ & & $59(49-69)$ & & \\
\hline & & & & Q3 & $50(40-60)$ & 0.4 & $56(46-65)$ & 0.2 & - \\
\hline & & & & Q4 & $58(49-66)$ & & $57(47-66)$ & & \\
\hline & & & & Q5 & $56(47-65)$ & & $49(41-57)$ & & \\
\hline Delayed bathing & $68(63-73)$ & $70(64-75)$ & 0.3 & Q1 & $63(53-72)$ & & $65(56-73)$ & & \\
\hline & & & & Q2 & $71(62-79)$ & & $68(58-77)$ & & \\
\hline & & & & Q3 & $71(61-80)$ & 0.8 & $71(60-80)$ & 0.2 & - \\
\hline & & & & Q4 & $67(57-76)$ & & $70(60-78)$ & & \\
\hline & & & & Q5 & $68(60-75)$ & & $73(64-80)$ & & \\
\hline
\end{tabular}

Note: $\mathrm{Cl}=$ confidence interval, $\mathrm{NA}=$ not applicable, $\mathrm{OR}=$ odds ratio, $\mathrm{SES}=$ socioeconomic status

*The $p$ value for OR for difference in coverage over time.

tQuintile 1 (Q1) was the poorest, and quintile 5 (Q5) was the least poor.

$\ddagger$ The $p$ value for OR for a 1-unit change in SES within each survey year.

$\S$ The $p$ value for interaction between SES and survey year, shown only for indicators with statistical evidence of coverage change from 2012 to 2015 (based on $p<0.05$ ). 
$0.001)$, facility delivery $(p=0.007)$, postnatal care for newborn $(p=0.01)$ and birth attendant's use of gloves $(p=0.04)$. By 2015, coverage for 2 of the access-to-care indicators had improved. Facility delivery increased from 76\% (459/604; 95\% Cl 71\%-80\%) in 2012 to $81 \%$ (475/584; $95 \% \mathrm{Cl} 77 \%-85 \%)$ in 2015, reaching $80 \%$ even among the poorest group of women. In addition, postnatal care for the mother increased from 54\% (324/604; 95\% Cl 48\%$59 \%)$ to $63 \%(365 / 584 ; 95 \% \mathrm{Cl} 58 \%-67 \%)$. Testing for an interaction between time and socioeconomic status showed no evidence that any socioeconomic status group benefited more than another for either of these indicators.

\section{Interpretation}

In 2012, the coverage of maternal and newborn health care in 3 diverse settings was suboptimal, with the poorest families consistently having lowest access and intervention coverage. Following 3 years of large-scale, community-based intervention, some improvements were observed. Notably, more women in Ethiopia and Uttar Pradesh had access to maternity care in 2015 than in 2012; however, this was not the case in Gombe State, where sociocultural barriers to access persisted, and the Boko Haram insurgency presented a barrier to accessing care..$^{23}$ In all 3 settings, coverage for early postnatal care remained low, despite strong government commitment to and intense nongovernment effort for community-based programming.

Improving outcomes for mothers and newborns requires not only structural changes in the provision of care, but also behaviour change by individuals, communities and health care providers. Such changes may take considerable time - longer than this study's duration - to achieve. ${ }^{24}$ Where changes did occur, they were of a similar magnitude for all socioeconomic groups, with the exception only of birth attendant's use of gloves in Ethiopia. However, because of the pre-existing inequities, this meant that the coverage of many indicators remained inequitable in 2015.

There is considerable evidence to support implementation of community-based interventions for maternal and newborn health. ${ }^{25-27}$ Our findings have both an optimistic and a pessimistic interpretation, in that families from all socioeconomic status groups benefited, but inequities have also persisted. ${ }^{28}$ In 2015, all 3 study settings were characterized as rural and poor with a high burden of mortality; the entire population was in need of better care. However, as population-level coverage increases, a more sophisticated examination of the patterns of inequity is required, ${ }^{29}$ along with greater agility in decision-making about how to target vulnerability. ${ }^{30,31}$ Meeting these requirements will necessitate more country-level coordination and leadership, with more investment in data that can be disaggregated for this purpose. ${ }^{32}$

It is also relevant to consider packages of care, rather than focusing on indicators independently. For example, if facility delivery increases, then so should indicators reflecting positive behaviours at birth, as observed in Ethiopia. ${ }^{33}$ Emphasis on packages of care demands a more quality-oriented, effective coverage approach to planning, implementation and measurement. ${ }^{34}$ Furthermore, it is crucial to understand why the poorest women receive the worst quality of care. One reason may be that they have the fewest choices in the type of provider they can access, because they lack the resources needed to bypass local facilities to seek better-quality care elsewhere. ${ }^{6,35,36}$

\section{Limitations}

The strengths of this study included examination of progress on a large scale, at 2 points in time, using the same measurement approach, with a relatively short recall period. However, the study was limited by its observational design, the inability to assess the impact of individual interventions associated with change and consideration of the magnitude of change only in areas that were experiencing multiple improvement efforts concurrently. Other limitations included reliance on women's self-reporting in response to interviewer-administered structured questionnaires, which may not always provide valid responses s7,38 $^{37}$ a limited sample size that did not permit further subgroup analyses. Results from the multiple interaction tests examining whether change was inequitable should be interpreted with caution, because the study was not explicitly powered for these tests.

\section{Conclusion}

Universal health coverage requires that countries strategize to reach the most vulnerable members of the population, who experience the worst health outcomes. In our study, representing a total population of more than 22 million people in Nigeria, Ethiopia and India, we found that the poorest families benefited in equal measure to the least poor families, for 8 maternal and newborn health care indicators, but without immediate redress of socioeconomic inequities in health care. To ensure that no one is left behind, specific efforts are needed to close these coverage gaps.

\section{References}

1. Victora CG, Requejo JH, Barros AJ, et al. Countdown to 2015: a decade of tracking progress for maternal, newborn, and child survival. Lancet 2016;387:2049-59.

2. Victora C, Requejo J, Boerma T, et al. Countdown to 2030 for reproductive, maternal, newborn, child, and adolescent health and nutrition. Lancet Glob Health 2016;4:e775-6.

3. Al-Janabi A, Al-Wahdani B, Ammar W, et al. Bellagio Declaration on highquality health systems: from a quality moment to a quality movement. Lancet Glob Health 2018;6:e1144-5.

4. Clark B, Preto N. Exploring the concept of vulnerability in health care. CMAJ 2018;190:E308-9.

5. Gwatkin DR. Trends in health inequalities in developing countries. Lancet Glob Health 2017;5:e371-2.

6. Arsenault C, Jordan K, Lee D, et al. Equity in antenatal care quality: an analysis of 91 national household surveys. Lancet Glob Health 2018;6:e1186-95.

7. Chopra M, Sharkey A, Dalmiya N, et al.; UNICEF Equity in Child Survival, Health and Nutrition Analysis Team. Strategies to improve health coverage and narrow the equity gap in child survival, health, and nutrition. Lancet 2012; 380:1331-40.

8. Countdown Equity Analysis Group; Boerma JT, Bryce J, Kinfu Y, et al. Mind the gap: equity and trends in coverage of maternal, newborn, and child health services in 54 Countdown countries. Lancet 2008;371:1259-67.

9. Callaghan-Koru JA, Nonyane BA, Guenther T, et al. Contribution of communitybased newborn health promotion to reducing inequities in healthy newborn care practices and knowledge: evidence of improvement from a three-district pilot program in Malawi. BMC Public Health 2013;13:1052.

10. Nonyane BAS, Ashish KC, Callaghan-Koru JA, et al. Equity improvements in maternal and newborn care indicators: results from the Bardiya district of Nepal. Health Policy Plan 2016;31:405-14. 
11. Lassi ZS, Haider BA, Bhutta ZA. Community-based intervention packages for reducing maternal and neonatal morbidity and mortality and improving neonatal outcomes. Cochrane Database Syst Rev 2010;(11):CD007754.

12. Glenton C, Colvin CJ, Carlsen B, et al. Barriers and facilitators to the implementation of lay health worker programmes to improve access to maternal and child health: qualitative evidence synthesis. Cochrane Database Syst Rev 2013; (10):CD010414.

13. Darmstadt GL, Marchant T, Claeson M, et al. A strategy for reducing maternal and newborn deaths by 2015 and beyond. BMC Pregnancy Childbirth 2013;13:216.

14. National Burea of Statistics (NBS); United Nations Children's Fund (UNICEF). Multiple indicator cluster survey 2016-17. National survey finding report. Abuja (Nigeria): NBS and UNICEF; 2017 Oct. [updated 2018 Feb.]. Available: www.unicef.org/ nigeria/sites/unicef.org.nigeria/files/2018-09/Nigeria-MICS-2016-17.pdf (accessed 2019 Feb. 1).

15. Global Health Observatory country views. Geneva: World Health Organization; 2016. Available: https://apps.who.int/gho/data/node.country (accessed 2019 Feb. 1).

16. Maternal mortality ratio (MMR) (per 100000 live births). Government of India, National Institution for Transforming India. Available: www.niti.gov.in/content/ maternal-mortality-ratio-mmr-100000-live-births (accessed 2019 Feb. 1).

17. Essential interventions, commodities and guidelines for reproductive, maternal, newborn and child health: a global review of the key interventions related to reproductive, maternal newborn and child health. Geneva: World Health Organization, Partnership for Maternal, Newborn \& Child Health; 2011. Available: www.who.int/pmnch/knowledge/publications/201112_essential_ interventions/en/ (accessed 2014 Aug. 13)

18. Makowiecka K, Marchant T, Betemariam W, et al. Characterising innovations in maternal and newborn health based on a common theory of change: lessons from developing and applying a characterisation framework in Nigeria, Ethiopia and India. BMJ Glob Health 2019;4:e001405.

19. Marchant T, Tilley-Gyado RD, Tessema T, et al. Adding content to contacts: measurement of high quality contacts for maternal and newborn health in Ethiopia, north east Nigeria, and Uttar Pradesh, India. PLoS One 2015;10:e0126840.

20. Allen E, Schellenberg J, Berhanu D, et al. Associations between increased intervention coverage for mothers and newborns and the number and quality of contacts between families and health workers: an analysis of cluster level repeat cross sectional survey data in Ethiopia. PLoS One 2018;13:e0199937.

21. Marchant T, Bryce J, Victora C, et al. Improved measurement for mothers, newborns and children in the era of the Sustainable Development Goals. J Glob Health 2016;6:010506.

22. DHS model questionnaires. Rockville (MD): DHS (Demographic and Health Surveys) Program. Available: www.dhsprogram.com/What-We-Do/Survey-Types/ DHS-Questionnaires.cfm (accessed 2019 Aug. 25).

23. Adeyanju O, Tubeuf S, Ensor T. Socio-economic inequalities in access to maternal and child healthcare in Nigeria: changes over time and decomposition analysis. Health Policy Plan 2017;32:1111-8.
24. Bee M, Shiroor A, Hill Z. Neonatal care practices in sub-Saharan Africa: a systematic review of quantitative and qualitative data. $J$ Health Popul Nutr 2018;37:9.

25. McCollum R, Gomez W, Theobald S, et al. How equitable are community health worker programmes and which programme features influence equity of community health worker services? A systematic review. BMC Public Health 2016;16:419.

26. Adjei GO, Kurtzhals JA, Rodrigues OP, et al. Amodiaquine-artesunate vs artemetherlumefantrine for uncomplicated malaria in Ghanaian children: a randomized efficacy and safety trial with one year follow-up. Malar J 2008;7:127.

27. Tangcharoensathien V, Mills A, Palu T. Accelerating health equity: the key role of universal health coverage in the Sustainable Development Goals. BMC Med 2015;13:101.

28. Victora CG, Vaughan JP, Barros FC, et al. Explaining trends in inequities: evidence from Brazilian child health studies. Lancet 2000;356:1093-8.

29. Victora CG, Barros AJ, Axelson $\mathrm{H}$, et al. How changes in coverage affect equity in maternal and child health interventions in 35 Countdown to 2015 countries: an analysis of national surveys. Lancet 2012;380:1149-56.

30. Sharma R, Scott H, Bhutta ZA. Enhancing implementation research within Canada's investments in the health of women and children globally. CMAJ 2017;189:E332-3.

31. Rasanathan K, Atkins V, Mwansambo C, et al. Governing multisectoral action for health in low-income and middle-income countries: an agenda for the way forward. BMJ Glob Health 2018;3(Suppl 4):e000890.

32. Grove J, Claeson M, Bryce J, et al.; Kirkland Group. Maternal, newborn, and child health and the Sustainable Development Goals - a call for sustained and improved measurement. Lancet 2015;386:1511-4.

33. Hill Z, Amare Y, Scheelbeek P, et al. 'People have started to deliver in the facility these days': a qualitative exploration of factors affecting facility delivery in Ethiopia. BMJ Open 2019;9:e025516.

34. Kruk ME, Gage AD, Arsenault C, et al. High-quality health systems in the Sustainable Development Goals era: time for a revolution. Lancet Glob Health 2018;6:e1196-252.

35. Sharma J, Leslie HH, Kundu F, et al. Poor quality for poor women? Inequities in the quality of antenatal and delivery care in Kenya. PLoS One 2017;12:e0171236.

36. Benova L, Tunçalp Ö, Moran AC, et al. Not just a number: examining coverage and content of antenatal care in low-income and middle-income countries. BMJ Glob Health 2018;3:e000779.

37. Munos MK, Stanton CK, Bryce J; Core Group for Improving Coverage Measurement for $\mathrm{MNCH}$. Improving coverage measurement for reproductive, maternal, neonatal and child health: gaps and opportunities. J Glob Health 2017;7:010801.

38. Bhattacharya AA, Allen E, Umar N, et al. Monitoring childbirth care in primary health facilities: a validity study in Gombe State, northeastern Nigeria. J Glob Health 2019;9:020411.

\section{Competing interests: None declared.}

This article has been peer reviewed.

Affiliations: Faculties of Infectious and Tropical Diseases (Marchant, Berhanu, Gautham, Umar, Armstrong Schellenberg) and of Epidemiology and Population Health (Beaumont, Makowiecka, Tomlin, Cousens, Allen), London School of Hygiene \& Tropical Medicine, London, UK; Ethiopian Public Health Institute (Berhanu) and JaRco Consulting (Tessema), Addis Ababa, Ethiopia; Sambodhi Research and Communications Pvt. Ltd. (Singh), New Delhi, India; Data Research and Mapping Consult (Usman), Abuja, Nigeria

Contributors: Tanya Marchant, Simon Cousens and Joanna Armstrong Schellenberg conceived the study. All of the other authors contributed to acquisition, analysis or interpretation of the data. All of the authors contributed to drafting the manuscript and revising it critically for important intellectual content, and to approval of the final version to be published. All of the authors agreed to be accountable for all aspects of the work.
Funding: This work was supported through a grant from the Bill \& Melinda Gates Foundation to the IDEAS project at the London School of Hygiene \& Tropical Medicine. The funder had no role in study design, data collection and analysis, decision to publish or preparation of the manuscript.

Data sharing: All data files are available from the COMPASS database of the London School of Hygiene \& Tropical Medicine (doi: 10.17037/ DATA.129).

Acknowledgements: The authors are grateful for support received by field teams and government officials in each geographic region during administration of the surveys. They also thank the many women who gave generously of their time during interviews.

Accepted: Oct. 15, 2019

Correspondence to: Tanya Marchant, Tanya.Marchant@lshtm.ac.uk 